\title{
Index of checklists
}

A

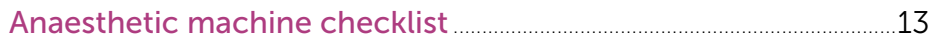

Anaesthetic planning questions _.................................................. 10

Anaphylaxis and allergic reactions .................................................... 52

B

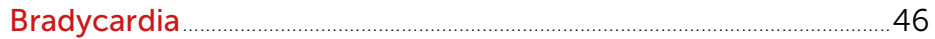

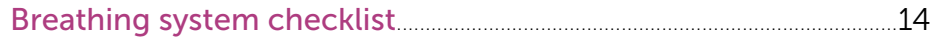

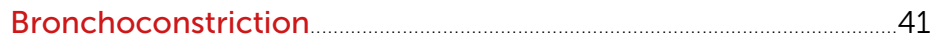

C

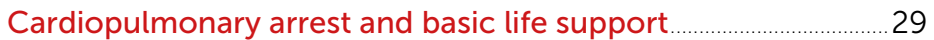

Cardiopulmonary resuscitation (CPR) drugs list ..............................31

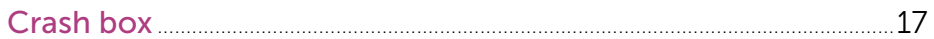

D

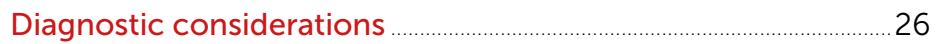

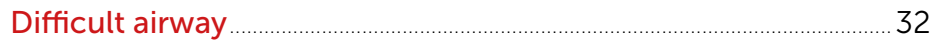

Difficult airway equipment checklist _......................................................

E

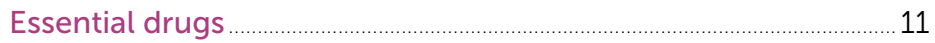

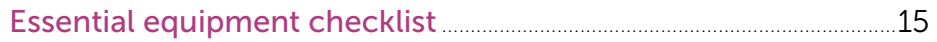

$\mathbf{H}$

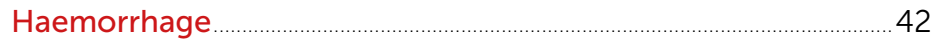

Hyperkalaemia - myocardial toxicity $\quad 50$

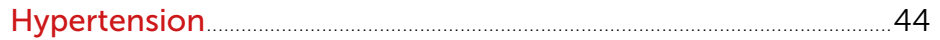

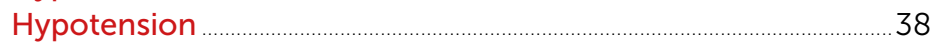

Hypoxaemia, desaturation and cyanosis ................................. 35

P

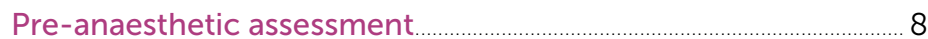

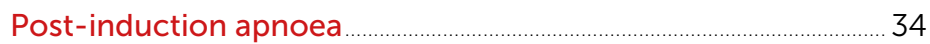

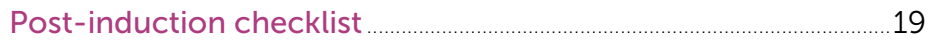

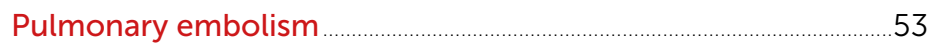

$\mathbf{R}$

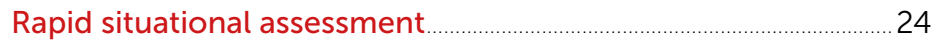

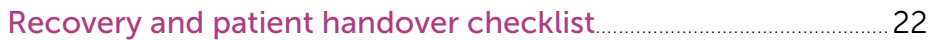

\section{S}

Safety checklist: before starting procedure ................................. 20

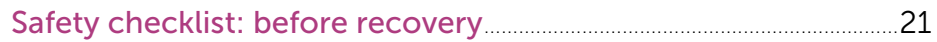

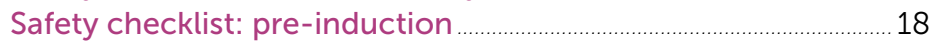

T

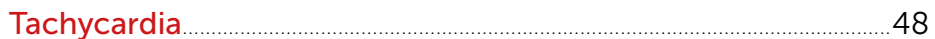

Troubleshooting: capnography ………................................... 56

Troubleshooting: pulse waveforms and pulse oximetry...............54 